\title{
Fungal Spore Aerosolization at Different Positions of a Growing Colony Blown by Airflow
}

\author{
Xian Li, Houli Fu* \\ School of Civil Engineering and Architecture, Linyi University, Linyi 276000, China
}

\begin{abstract}
The possible role of bioaerosols in the transmission of severe acute respiratory syndrome coronavirus-2 (SARS-CoV-2) causing the coronavirus disease 2019 (COVID-19) has recently been highlighted. A bioaerosol can be comprised of bacterial cells, fungal spores and viruses. Aerosolized fungal spores in indoor environments can cause adverse health effects. As a colony propagates from the center to the perimeter, the age of fungal spores and thus the adhesion force to the colony can be much different. The spore detachment may vary according to the growing position of the spores on a colony in relation to the airflow. This study investigated the aerosolization of fungal spores at different positions of a colony. A fungal colony was divided into a quantity of sub colonies according to the age distribution. Each sub colony was subjected to airflow in a wind tunnel to determine the released spores by two count methods. The results revealed that the initial spore density, the spore release rate, and the spore release proportion for the central sub colony were all significantly higher than that for the sub colony at the edge. The spore release rate for the central sub colony was approximately 2.6 times that at the edge. Spores growing at the center of the colony were aerosolized more easily than that growing at the outer edge. Growth age is a significant factor in the difference of spore aerosolization between sub colonies.
\end{abstract}

Keywords: Fungal spore; Bioaerosol; Indoor environment; Growing position; COVID-19.

\section{INTRODUCTION}

The world pandemic of the coronavirus disease 2019 (COVID-19) has aroused people's enthusiasm for research on the role of bioaerosols in the transmission of severe acute respiratory syndrome coronavirus-2 (SARS-CoV-2) (Chen and Cheng, 2020; Sannino et al., 2020). The potential risk for airborne transmission of SARS-CoV-2 has been demonstrated in the indoor environments (Ahlawat et al., 2020; Lednicky et al., 2020). A bioaerosol is an airborne collection of biological material, which can be comprised of bacterial cells, fungal spores and viruses. Bioaerosol contamination accounts for approximately $25 \%$ of the indoor air pollution (Nevalainen et al., 2015; Adams et al., 2016; Wu and Wong, 2020). Among different kinds of microorganisms, fungi are a heterogeneous group and have a significant impact on human pathology (Acerbi et al., 2016; Xiao et al., 2018). Airborne fungal propagules can cause poor indoor air quality and are associated with inflammation and infection in human beings (Palmatier, 2007; Feigley et al., 2013; Szulc et al., 2020). In addition, fungi contribute to allergies,

\footnotetext{
${ }^{*}$ Corresponding author.

Tel.: +86 5397258000

E-mail address: fuhouli@lyu.edu.cn
}

dermatomycosis, and sick building syndrome (Bakker et al., 2020; Wang et al., 2020).

The warm and moist conditions indoors are ideal environments for fungal propagation. If the humidity level is favorable, fungal spores can germinate and develop into foot cells on the surface of building materials (López-Gómez et al., 2013; Liu et al., 2015; Li et al., 2016). The foot cells grow from the center to the outer edge and a mat-like structure known as mycelium is then formed. After a period of vegetative growth, the foot cells grow into air and form aerial hyphae. The aerial hyphae can differentiate into conidiophores, which give rise to a large number of spores (Wang et al., 2020; Gopalakrishnan et al., 2016). Previous studies have showed that significant amounts of visible molds were found in ceiling tiles and wallpapers (Nielsen, 2003). The density of fungal spores in the floor dust was found to be as high as $1.5 \times 10^{5} \# \mathrm{mg}^{-1}$ (Dannemiller et al., 2017).

Once fungi have developed on a building material, the building material may be as a source to release fungal propagules into the indoor air. For many fungal species, the connection between two adjacent spores is a septum. The septum can be easily broken by mechanical disturbances (Górny et al., 2001). Possible consequences are the detachment of fungal propagules from colonies. Aerosolized fungal spores can be delivered into indoor environments by airflow and inhaled by the human body.

Factors that affect spore aerosolization can be divided into 
external and internal factors. For the external factor, air speed, relative humidity of the airflow, and vibration of the growth substrate were found to significantly affect spore detachment (Frankel et al., 2013). Spore detachment from colonies was mainly caused by the aerodynamic mechanism (Madelin, 1994). The study of spore aerosolization for seven typical indoor fungi found that the spore release rate increased with the blowing air speed (Zoberi, 1961). Relative humidity was found a strong negative correlation with the spore release from building materials (Pasanen et al., 1991; Madsen, 2012). In addition, mechanical vibration could significantly increase the spore release dozens of times compared to that without vibration (Górny et al., 2001).

For the internal factor, fungal species and age of colonies have also an effect on the spore release. Spore release can be much different from different fungal species. The spores of Aspergillus were more easily detached from colonies than those of Cladosporium (Zoberi, 1961; Górny et al., 2001). The age of a fungal colony refers to the growth time of a colony on the surface of solid substrates. The connection between spores for the older colony was much weaker than that for the younger colony, thus, the detachment forces of spores for the older colony were smaller (Górny et al., 2001). The spores of the older colony were more easily aerosolized than those of the younger colony.

Note that when a colony propagates from the center to the perimeter, the age distribution of a fungal colony is not homogeneous. The age of spores at the center of the colony is older than that at the edge. Because the younger colony has stronger connection between spores than the older colony, the forces required to detach spores at the center are smaller than those at the edge. Spore detachment may vary according to the growing position of the spores for a colony. Thus, the spore aerosolization at different positions of the colony can be much different.

The above review reveals that the aerosolization of fungal spores can be affected by external and internal factors. Up to now, the differences in aerosolization of fungal spores in relation to the growing position in a colony have been unclear. The aim of this study is to investigate the release of fungal spores at different positions of a colony when blown by airflow. A colony of Aspergillus niger (A. niger) was divided into a quantity of sub colonies according to the age distribution. Each sub colony was subjected to blowing air to estimate the spore release rate and the spore release proportion. The aerosolization tests of spores from colonies at different ages was also conducted in order to estimate effect of the age of colonies on the spore release.

\section{MATERIALS AND METHODS}

In this section, schematics of the aerosolization experiments are presented first. An introduction to the test microorganism is then addressed.

\section{Aerosolization Tests}

A wind tunnel was constructed for aerosolization tests, as illustrated in Fig. 1. After incubation, a fungal colony (a whole colony or a sub colony) was placed on a holder in the front of the ventilation duct. The air was forced through the HEPA (high efficiency particulate air) filter, and the clean air blew the test colony. Fungal spores were released from the colonies and some of the airborne spores were collected by a bioaerosol sampler. The air speed was controlled by a variable frequency device connected to the fan. To make the aerosolized spores uniformly in the ventilation duct for sampling, two sets of windmills were installed in the middle of the duct. The outlet filter collected all surplus microbial particles to prevent pollution of indoor air.

The ventilation duct was $150 \mathrm{~cm}$ long with a $30 \mathrm{~cm}$ $\times 30 \mathrm{~cm}$ cross-sectional area. To make the incoming air flow uniformly, honeycombs ( $3.175 \mathrm{~mm}$ cell size, $25.4 \mathrm{~mm}$ thick) were installed at the exit of the contraction section (Kim et al., 2016). The windmill was driven by airflow. The surface of the windmill was smooth to reduce adhesion of spores on it. The distance between the test colony and the bioaerosol sampler was $120 \mathrm{~cm}$. The bioaerosol sampler was an openface filter holder with a $37 \mathrm{~mm}$ sterile polycarbonate filter (0.8 $\mu \mathrm{m}$ pore size; Whatman Corp., UK). The sampling flow of the filter sampler was $20 \mathrm{~L} \mathrm{~min}^{-1}$.

Two methods were used to count the spores collected on the filters, i.e., colony forming units (CFU) count and microscopic count. A colony forming unit (CFU) is a unit commonly used to estimate the concentration of fungal spores in a test sample. For the CFU count method, the filters containing collected spores were placed in a sterile petri dish containing $5 \mathrm{~mL}$ sterilized water. The spores were suspended into the sterilized water by a pipette $(1 \mathrm{~mL}$; Thermo Fisher Corp., USA). Approximately $200 \mu \mathrm{L}$ of spore suspensions after dilution were inoculated onto the Sabouraud dextrose agar (SDA) plate for quantification (Feigley et al., 2013). For the microscopic count method, the filters were placed on

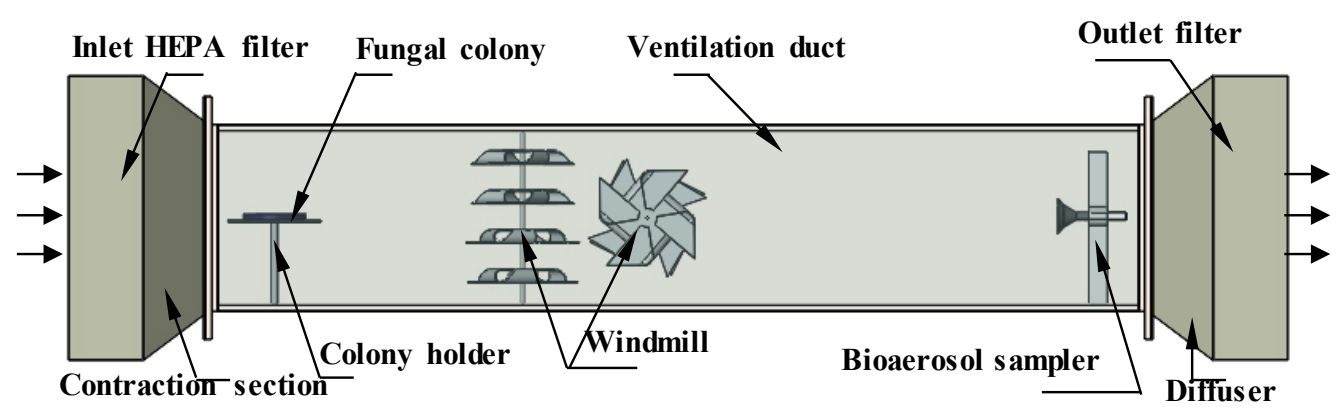

Fig. 1. Schematic diagram of the wind tunnel for aerosolization tests. 
glass slides and the collected spores were counted by an optical microscope (Model CX41; Olympus Corp., Japan). Because the polycarbonate filters have good transmission of light, the spores collected onto them could be directly counted under the optical microscope.

The experiments were conducted at the air speed of $5 \mathrm{~m} \mathrm{~s}^{-1}$. This blowing speed was the typical value for the ventilation duct and also the maximum value in the indoor environments (Wang et al., 2012). Each test lasted for $15 \mathrm{~min}$. The results

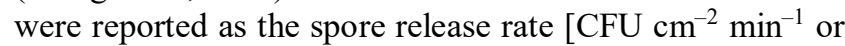
$\left.\# \mathrm{~cm}^{-2} \mathrm{~min}^{-1}\right]$ and the spore release proportion (\%). Spore release rate was defined as the quantity of released spores within one minute per unit area of fungal colony. Spore release proportion was determined as the ratio of the quantity of released spores to the total quantity of spores for the test colony. The temperature and relative humidity of the airflow monitored by a hygrothermograph (Model 179-DTH; Apresys Corp., USA) were $17-19^{\circ} \mathrm{C}$ and $25-27 \%$, respectively. In between the aerosolization tests, the ventilating duct was first cleaned with $70 \%$ ethanol and then purged by clean air (Mensah-Attipoe et al., 2016). Each aerosolization experiment for a specific sub colony and growth age was repeated five times.

To test the uniformity of the aerosolized spores at the location of the bioaerosol sampler, the sampler collected released spores at nine isometric sampling points. Each aerosolization test for a single sampling point required a new parallel colony. In addition, some of airborne spores might adhere to the surface of the windmill and would consequently have been omitted by the bioaerosol sampler. After each test, the adhered spores were sampled by the sterile cotton for quantification and counted into the released spores.

The colony was observed before and after air blowing by scanning electron microscope (SEM) analysis. Chemical fixation technique for the colony was used to prepare specimens for SEM, and the details were shown in the previous study (Mims et al., 1988). In addition, the fungal propagules were collected on the glass slide and photographed by the optical microscope.

\section{Preparation of Test Colonies}

The fungal species of $A$. niger (2089; Center of Industrial Culture Collection, China) was selected as the test fungus. This genus was chosen because it commonly breeds in indoor environments, and it is one of the indicator species for mold problems (Li et al., 2016).

The fungal strain was first grown on the malt extract agar slant for seven days before inoculation on the SDA plates. A vaccination needle was burned for sterilization and then dipped a small amount of $A$. niger spores from the malt extract agar slant. The spores adhering to the vaccination needle were inoculated onto the nutrient agar plate. The whole operation was conducted beside the flame of the alcohol burner inside a clean bench (Model CDA-1080; Shangjing Corp., China).

After inoculation, the agar plates were incubated in a dark incubator. The incubation conditions of $A$ niger colonies are shown in Table 1 . The culture temperature was $28^{\circ} \mathrm{C}$ and the relative humidity $(\mathrm{RH})$ inside the culture dish was close to $100 \%$. The colony were incubated for seven consecutive days which resulted in abundant fungal growth on the agar plates. The colony diameter was measured once a day using the cross measurement method. Cross measurement is a method which measures the colony diameter two times horizontally and vertically. The average value was determined as the colony diameter. Temperature and humidity inside the incubator were monitored by the hygrothermograph.

After cultivation, the 7-day-old fungal colony was divided into six sub colonies according to the measured colony diameters, as shown in Fig. 2. Because the size of the 1-dayold colony was undersize, the first two days' sub colonies were included into the $\mathrm{D}_{2}$ sub colony. The age of the $\mathrm{D}_{2}$ sub colony was closed to six days. The $\mathrm{D}_{3}$ sub colony means the third days' sub colony whose age was five days. Like the $\mathrm{D}_{3}$ sub colony, the ages of $\mathrm{D}_{4}, \mathrm{D}_{5}$, and $\mathrm{D}_{6}$ sub colony were four, three, and two days, respectively. Because the fungal colony grew from the center to the outer edge and formed a heterogeneous age distribution, the age of the central sub colony was older than that of the sub colony at the edge.

For measuring the initial spore density, the sub colony was placed in a sterilized petri dish containing $10 \mathrm{~mL}$ of sterilized water. The spores growing on the agar plate were scraped gently by an inoculating loop. Spore suspensions were then vibrated for $10 \mathrm{~min}$ by a vortex touch mixer. The spore concentrations were measured by CFU count and microscopic count using the hemacytometer, respectively. The initial spore density was reported as CFU $\mathrm{cm}^{-2}$ and $\# \mathrm{~cm}^{-2}$ for the two count methods.

\section{Data Analysis}

The initial spore density, the spore release rate, and the spore release proportion were log-normally distributed. Therefore, geometric mean (GM) and geometric standard deviation (GSD) were calculated. Experimental data were statistically analyzed using one way analysis of variance (ANOVA) model. Differences of $P<0.05$ were considered statistically significant (Mensah-Attipoe et al., 2016).

\section{RESULTS AND DISCUSSION}

\section{Conidiophores and Released Propagules Subjected to Different Blowing Speeds}

Fig. 3 compares the morphology of $A$. niger colonies before and after air blowing. Before the aerosolization test,

Table 1. Incubation conditions of $A$ niger colonies.

\begin{tabular}{llll}
\hline Item & Value & Item & Value \\
\hline Nutrient content & Glucose $\left(40 \mathrm{~g} \mathrm{~L}^{-1}\right)$, peptone $\left(10 \mathrm{~g} \mathrm{~L}^{-1}\right)$, agar $\left(15 \mathrm{~g} \mathrm{~L}^{-1}\right)$ & Light condition & No light \\
Temperature & $28^{\circ} \mathrm{C}$ & Incubation time & 7 days \\
Relative humidity & $\approx 100 \%$ & & \\
\hline
\end{tabular}




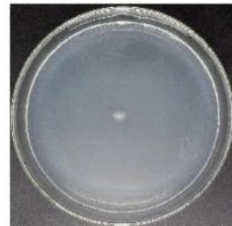

$1[d]$

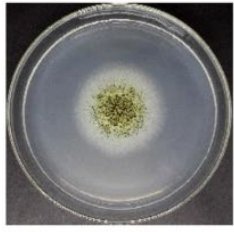

$4[d]$

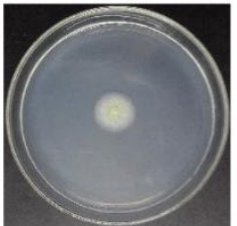

$2[d]$

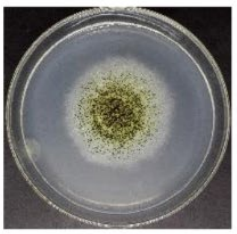

$5[d]$

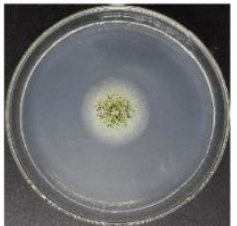

$3[d]$

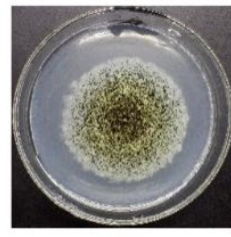

$6[d]$
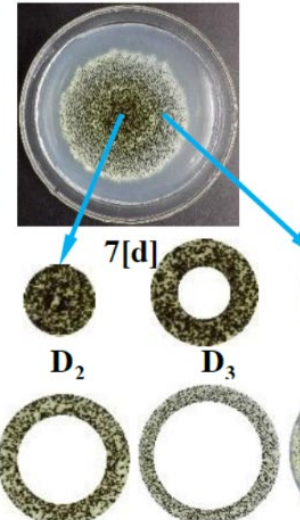

$\mathbf{D}_{6}$

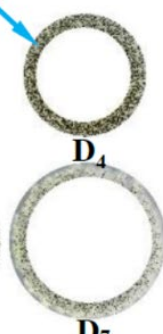

$\mathbf{D}_{7}$

Fig. 2. Evolution of $A$. niger colonies in seven consecutive days and division of the 7-day-old colony into six sub colonies.

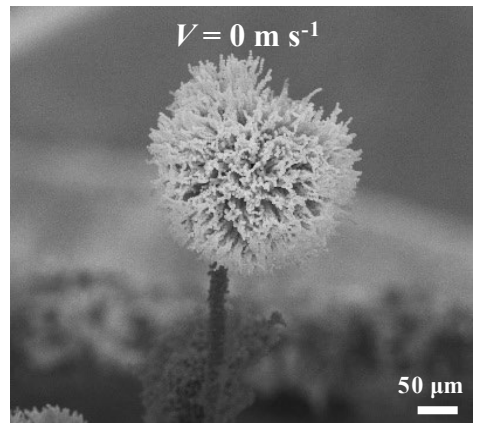

(a)

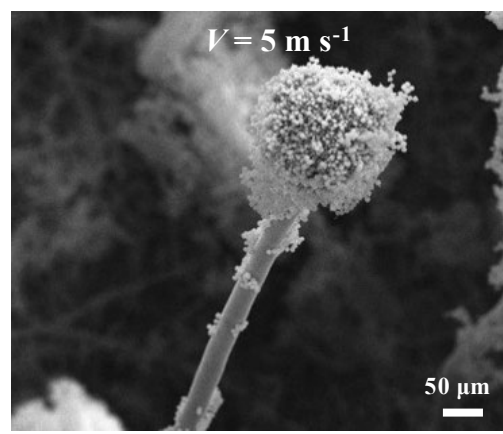

(b)

Fig. 3. Images of conidiophore under the SEM investigation: (a) before air blowing; (b) after air blowing at the air speed of $5 \mathrm{~m} \mathrm{~s}^{-1}$.

the conidiophore stalk was vertically erect, as shown in Fig. 3(a). After the aerosolization test with the air speed of $5.00 \mathrm{~m} \mathrm{~s}^{-1}$, the conidiophore stalk was blown awry and inclined approximately $30^{\circ}$ from the vertical, as shown in Fig. 3(b). In addition, the conidial head became smaller, and a certain quantity of spores were detached from their conidiophore. Conidial head is the sporogenous structure of the $A$. niger colony.

Fig. 4 presents the collected propagules of $A$. niger on the microscope slides at different blowing speeds for the 7-dayold colony. At the lower air speed of $5 \mathrm{~m} \mathrm{~s}^{-1}$, the particles released from the $A$. niger colony included isolated spores and spore aggregates, as well as pimping hyphal fragments. At the higher air speed of $10 \mathrm{~m} \mathrm{~s}^{-1}$, larger hyphae were released from fungal colonies. The conidiophore suffered greater drag force at the higher blowing speed than that at the lower blowing speed. Hence, the mechanical joint between the hyphae and the conidiophore were overcome by the aerodynamic force, and the hyphae were released from the colony.

\section{Initial Spore Density and Spore Release Rate for Different Sub Colonies}

The initial spore density for the six sub colonies is shown in Fig. 5. Both methods revealed that the spore density decreased from the center to the edge of the colony. For the
$\mathrm{D}_{2}$ sub colony, the spore density determined by microscopic count method was approximately $5.76 \times 10^{6} \mathrm{\#} \mathrm{cm}^{-2}$, which was significantly higher than that for the $\mathrm{D}_{7}$ sub colony (4.27

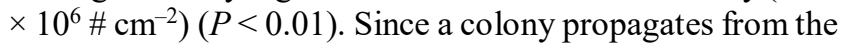
center to the perimeter, the age of the central sub colony is older than that of the sub colony at the edge. More spores were produced at each conidiophore for the central sub colony.

Fig. 6 compares the spore release rates for the six sub colonies at the blowing air speed of $5 \mathrm{~m} \mathrm{~s}^{-1}$. There was obvious dependence of the spore release rate on the growing position of a colony. Overall, the data obtained from CFU and microscope counts confirmed that the spore release rate decreased from the $\mathrm{D}_{2}$ sub colony to the $\mathrm{D}_{7}$ sub colony. $\mathrm{CFU}$ is a unit used to estimate the quantity of fungal spores for a colony. The release rates for the $\mathrm{D}_{2}$ sub colony were $4.55 \times$ $10^{3} \mathrm{CFU} \mathrm{cm} \mathrm{min}^{-1}$ and $5.11 \times 10^{3} \# \mathrm{~cm}^{-2} \mathrm{~min}^{-1}$ for the two methods, while the values for the $\mathrm{D}_{7}$ sub colony was $1.75 \times$

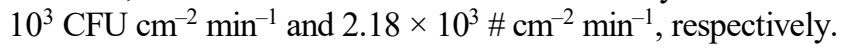
The spore release rate for the central sub colony $\left(D_{2}\right.$ sub colony) was approximately 2.6 times that for the sub colony at the edge ( $D_{7}$ sub colony). The results indicated that the spore release rate at the center of the colony was significantly higher than that at the edge.

Our data for the spore release rates were found several times higher than the data reported by Tucker et al. 2007), who investigated fungal spores release of $A$. niger from 


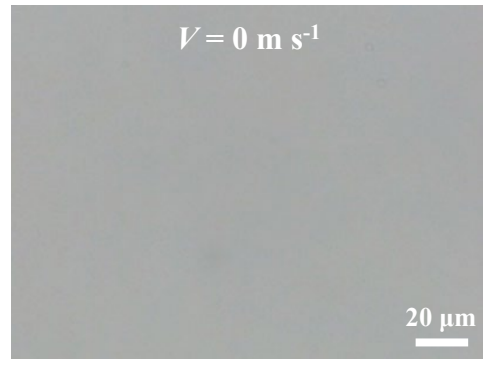

(a)

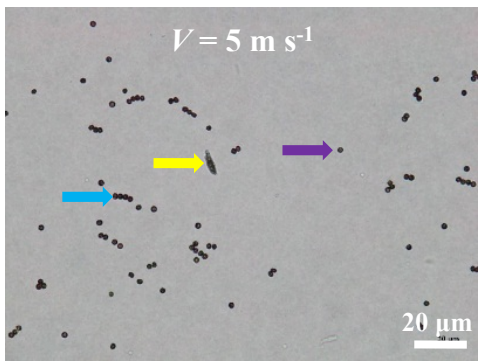

(b)

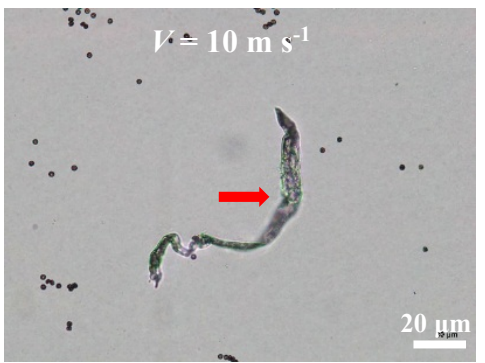

(c)

Fig. 4. Micrographs of fungal propagules collected by the microscope slide at different air speeds: (a) $0 \mathrm{~m} \mathrm{~s}^{-1}$; (b) $5 \mathrm{~m} \mathrm{~s}^{-1}$; (b) $10 \mathrm{~m} \mathrm{~s}^{-1}$.

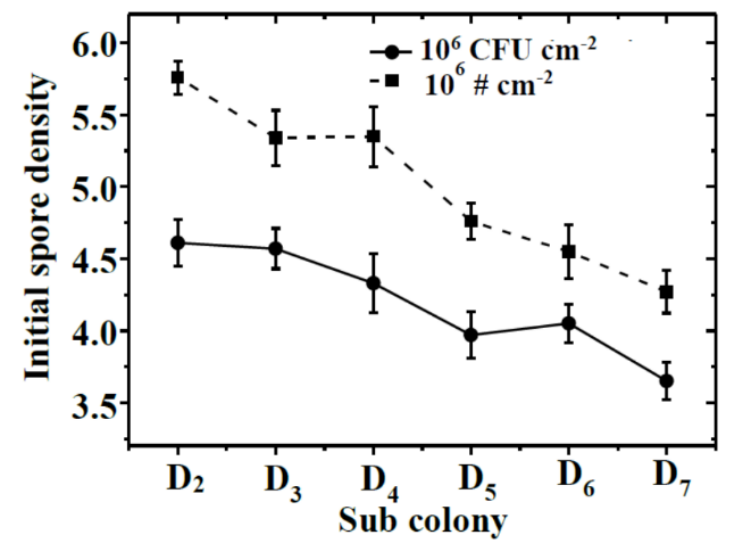

Fig. 5. Initial Spore density before aerosolization tests for the six sub colonies

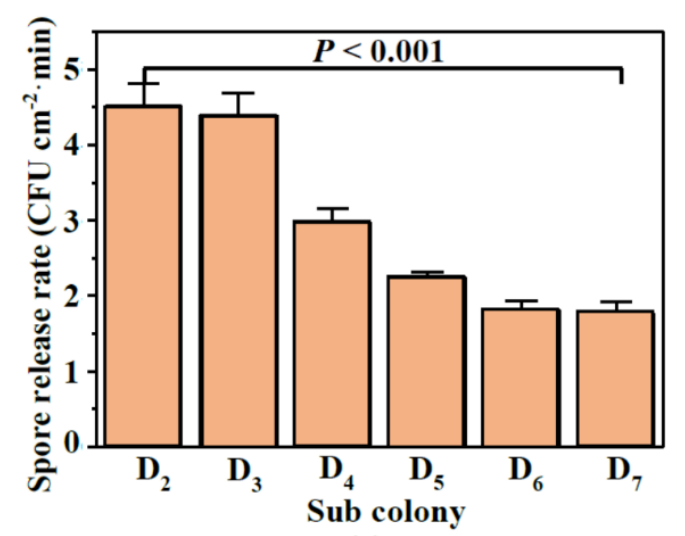

(a)

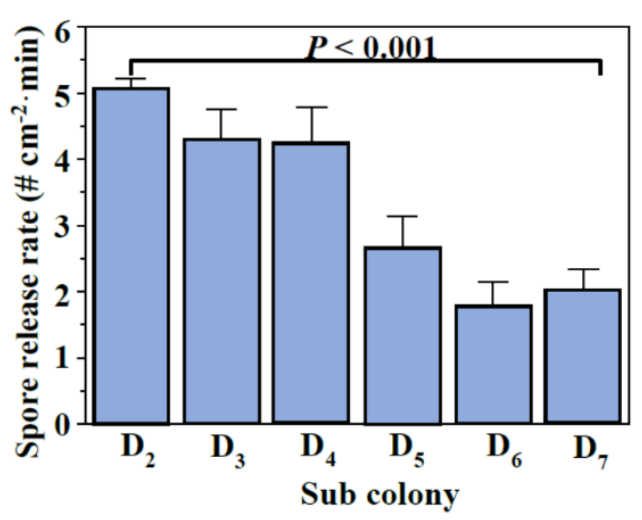

(b)

Fig. 6. Variation in the spore release rate for different sub colonies, where error bars indicate the standard deviations of five repeated tests: (a) CFU count; (b) microscope count

gypsum wallboards. This may be mainly because of the differences in air speeds. As mentioned above, air speed has a direct positive correlation with spore release beyond a threshold speed. Tucker et al. (2007) reported the air speed of $1.6 \mathrm{~m} \mathrm{~s}^{-1}$, whereas the air speed of $5 \mathrm{~m} \mathrm{~s}^{-1}$ was used in the present study. The drag force exerted on the fungal spores under the blowing speed of $5 \mathrm{~m} \mathrm{~s}^{-1}$ was much greater than that under the blowing speed of $1.6 \mathrm{~m} \mathrm{~s}^{-1}$. Thus, more spores were aerosolized from the colony subjected to the higher air speed.

\section{Spore Release Proportion for Different Sub Colonies}

Fig. 7 shows the spore release proportions for the six sub colonies at the air speed of $5 \mathrm{~m} \mathrm{~s}^{-1}$. Similar to the spore release rate, the spore release proportion of $A$. niger colonies had clear trend as a function of the growing position of a colony. The value of spore release proportion for the $\mathrm{D}_{2}, \mathrm{D}_{3}$, $\mathrm{D}_{4}, \mathrm{D}_{5}, \mathrm{D}_{6}$, and $\mathrm{D}_{7}$ sub colonies were $1.47 \%, 1.44 \%, 1.03 \%$, $0.85 \%, 0.67 \%$, and $0.73 \%$, respectively (CFU count). The release proportion for the $\mathrm{D}_{2}$ sub colony was approximately 2.0 times that for the $\mathrm{D}_{7}$ sub colony. The data demonstrated 


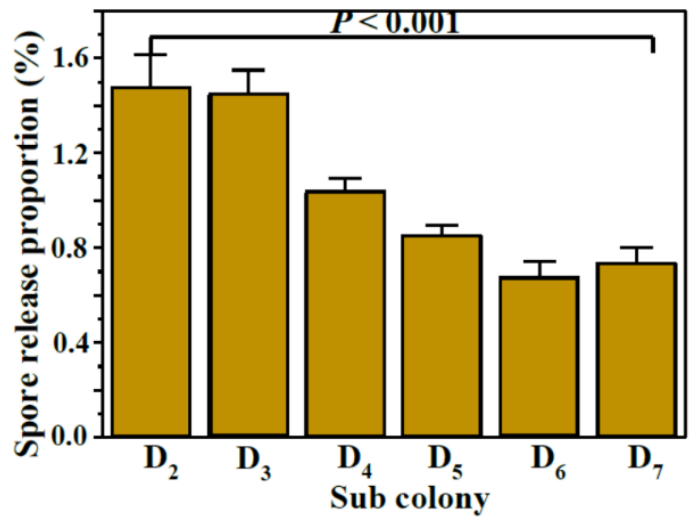

(a)

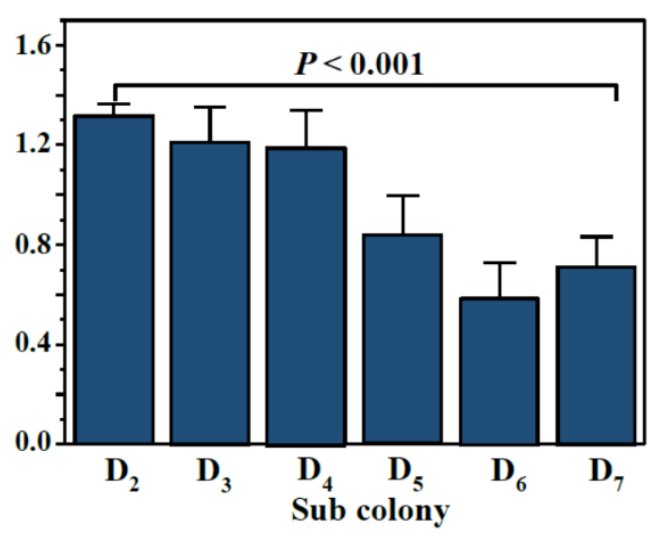

(b)

Fig. 7. Variation in the spore release proportion for different sub colonies, where the error bars indicate the standard deviation of five repeated tests: (a) CFU count; (b) microscope count.

that only a small fraction of spores was aerosolized from the colony. The proportion of the spores that remained attached to the colony exceeded $98.5 \%$. These findings agree well with the data reported in previous laboratory studies (Sivasubramani et al., 2004), in which low release proportion values were reported for other fungal species.

The results showed that the spores for the central sub colony were more easily aerosolized than that for the sub colony at the edge. This may be due to the heterogeneous age distribution of the colony. The age of spores in the center of the colony is the oldest, while the age at the outer edge is the youngest. For an older sub colony, the septum between two adjacent conidia is more easily broken by disturbance forces. Hence, the force required to detach spores from the central sub colony was smaller than that for the sub colony at the outer edge.

Different from other sub colonies, the spore release proportion for the $\mathrm{D}_{7}$ sub colony was greater than that for the $\mathrm{D}_{6}$ sub colony. This may be mainly because of the boundary layer of the airflow. In this investigation, the whole colony was divided into many annuli, as shown in Fig. 2. When the sub colony was subjected to air blowing, a boundary layer was formed and continuously developed with the flow development. The local air speeds at the spores at different positions of the colony might had a certain difference. Thus, spore aerosolization varied in accordance with their positions on the colony in relation to the airflow. Because the diameter of the $\mathrm{D}_{7}$ sub colony was largest among these sub colonies, the boundary layer had the greatest impact on the spore aerosolization. The measurements in this study did not take into account the above variations. More efforts have to clarify the above issues.

To validate the above hypothesis, the spore release in relation to growth age of the fungal colonies was investigated. Fig. 8 shows the spore release proportion for the $A$. niger colony at two different growth ages at the air speed of $5 \mathrm{~m} \mathrm{~s}^{-1}$. The 8-day-old colony showed significantly higher spore released proportion $(1.30 \%)$ than the 3 -day-old colony $(0.74 \%)$ (CFU count) $(P<0.05)$. The spore release proportion for the older colony was 1.76 times that for the younger colony. Our data support the previous findings that the spores release proportion of Penicillium chrysogenum and Trichoderma harzianum from wet gypsum boards depended on the age of fungal growth, ranging from $0.8 \%$ to $6.7 \%$ and $0.02 \%$ to $1.02 \%$, respectively (Kildesø et al., 2002).

The above results show that growth age is a significant factor in the difference of the spore release between the central sub colony and the sub colony at the edge. In addition, when a colony germinates from the center and then spreads to the perimeter, the micro environmental parameters, such as relative humidity and temperature, may vary and affect spore detachment forces from colonies. These variations may also lead to the differences of the spore aerosolization at different positions of a colony.

\section{Limitation of this Study and Outline of Future Research}

The spore release rate and the spore release proportion were estimated from the quantity of collected spores by the filter sampler. Isokinetic sampling might not be assured when extracting air samples. In addition, some of the airborne spores might had settled on surfaces of the test section and would consequently have been omitted by the bioaerosol sensor.

Fungal spore aerosolization is affected by fungal species (Zoberi, 1961; Górny et al., 2001). This investigation adopted the pure $A$. niger species for the aerosolization tests. The results of aerosolization tests for $A$. niger may not apply to other fungi.

Environmental factors, such as relative humidity, temperature, nutrition content of the solid substrate, can affect spore aerosolization (Feigley et al., 2013). Relative humidity was found a negative correlation with the spore detachment (Madsen, 2012). Fungal colonies prefer warmer environment, and the binding force between fungal spores is affected by temperature. Because this study focused on the internal factor that affect spore aerosolization, comparison of the above environmental factors to the spore release were not carried out. Further research has to clarify the above issues.

To avoid the interference of uncertainty, the $A$ niger colony was grown on the SDA plate. For estimating spore aerosolization at different positions of a colony from the 


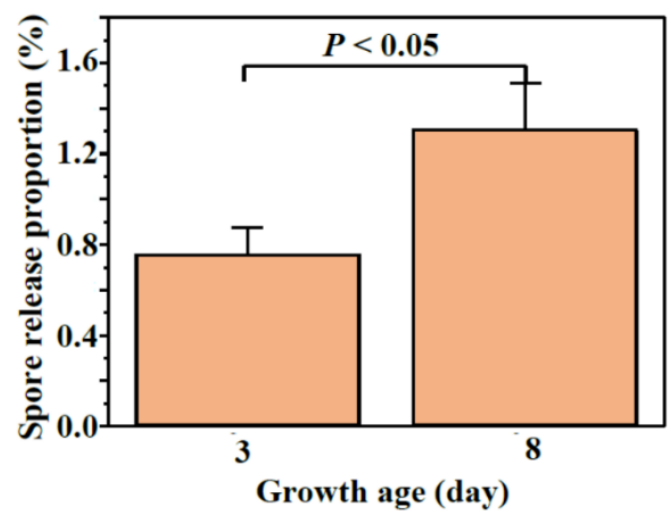

(a)

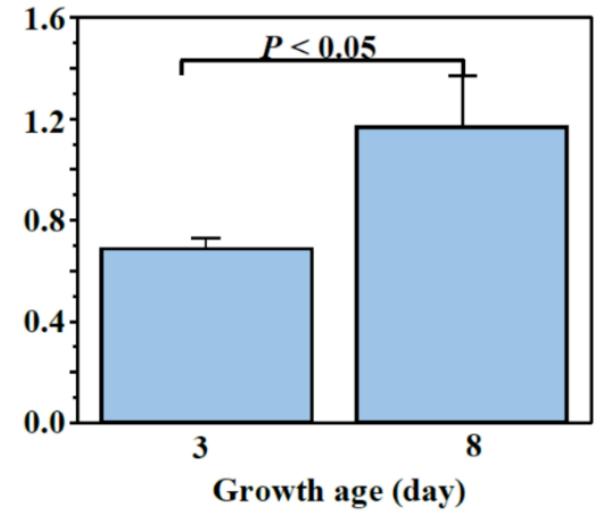

(b)

Fig. 8. Effect of age on the spore release proportion under the air speed of $5 \mathrm{~m} \mathrm{~s}^{-1}$, where the error bars indicate the standard deviation of five repeated tests: (a) CFU count; (b) microscope count.

general building material, a researcher may have to measure the spore release rate for the sub colonies on the specific material. Nevertheless, one may use the results of this study for a rough estimation, because the spore aerosolization is mainly affected by their growth age.

\section{CONCLUSIONS}

In this study, aerosolization of Aspergillus niger ( $A$. niger) spores at different positions of a colony subject to air blowing was investigated. It was found that there were great variations in visible behavior of $A$. niger colonies after air blowing. At the higher blowing air speed, larger hyphae could be detached from fungal colonies because of the greater drag force. The initial spore density, the spore release rate, and the spore release proportion all had clear trend as a function of the growing position of a colony. The spore release rate at the center of the colony was approximately 2.6 times that at the edge, while the ratio for the spore release proportion was approximately 2.0. The results indicated that the spores in the center of the colony were aerosolized more easily than those at the edge.

The age of the fungal colony was a significant factor in the difference of spore aerosolization at different positions of the colony. The required forces to detach spores increased from the center to the edge of the colony. The results suggest that the potential hazard of center sub colony is higher than that of the sub colony at the edge.

\section{ACKNOWLEDGMENTS}

This research received no external funding.

\section{REFERENCES}

Acerbi, E., Chénard, C., Miller, D., Gaultier, N.E., Heinle, C.E., Chang, V.W., Uchida, A., Drautz-Moses, D.I., Schuster, S.C. and Lauro, F.M. (2017). Ecological succession of the microbial communities of an air conditioning cooling coil in the tropics. Indoor Air 27: 345-353. https://doi.org/10.1111/ina.12306
Adams, R.I., Bhangar, S., Dannemiller, K.C., Eisen, J.A., Fierer, N., Gilbert, J.A., Green, J.L., Marr, L.C., Miller, S.L., Siegel, J.A., Stephens, B., Waring, M.S. and Bibby, K. (2016). Ten questions concerning the microbiomes of buildings. Build. Environ. 109: 224-234. https://doi.org/1 0.1016/j.buildenv.2016.09.001

Ahlawat, A., Wiedensohler, A. and Mishra, S.K. (2020). An overview on the role of relative humidity in airborne transmission of SARS-CoV-2 in indoor environments. Aerosol Air Qual. Res. 20: 1856-1861. https://doi.org/10. 4209/aaqr.2020.06.0302

Bakker, A., Siegel, J.A., Mendell, M.J., Prussin, A.J., Marr, L.C. and Peccia, J. (2020). Bacterial and fungal ecology on air conditioning cooling coils is influenced by climate and building factors. Indoor Air 30: 326-334. https://doi.org/10.1111/ina.12632

Chen, C.H.S. and Cheng, T.J. (2020). Reduction of influenza and enterovirus infection in Taiwan during the COVID-19 pandemic. Aerosol Air Qual. Res. 20: 20712074. https://doi.org/10.4209/aaqr.2020.05.0248

Dannemiller, K.C., Weschler, C.J. and Peccia, J. (2017). Fungal and bacterial growth in floor dust at elevated relative humidity levels. Indoor Air 27: 354-363. https://doi.org/10.1111/ina.12313

Feigley, C., Khan, J., Salzberg, D., Hussey, J., Attaway, H., Steed, L., Schmidt, M. and Michels, H. (2013). Experimental tests of copper components in ventilation systems for microbial control. HVACR Res. 19: 53-62. https://doi.org/10.1080/10789669.2012.735150

Frankel, M., Hansen, E.W. and Madsen, A.M. (2013). Effect of relative humidity on the aerosolization and total inflammatory potential of fungal particles from dustinoculated gypsum boards. Indoor Air 24: 16-28. https://doi.org/10.1111/ina.12055

Gopalakrishnan, S., Devassikutty, A.K., Mathew, M., Ayyappan, D., Thiagarajan, S. and Raghunathan, R. (2016). Passive release of fungal spores from synthetic solid waste surfaces. Aerosol Air Qual. Res. 16: 14411451. https://doi.org/10.4209/aaqr.2015.07.0438

Górny, R.L., Reponen, T., Grinshpun, S.A. and Willeke, K. (2001). Source strength of fungal spore aerosolization 
from moldy building Material. Atmos. Environ. 35: 4853 4862. https://doi.org/10.1016/s1352-2310(01)00261-8

Kildesø, P., Madsen, H. and Wilkins, K. (2002). Fungal spores from wet gypsum boards relationship between release and age of culture. Indoor Air 400.

Kim, Y., Wellum, G., Mello, K., Strawhecker, K.E., Thoms, R., Giaya, A. and Wyslouzil, B.E. (2016). Effects of relative humidity and particle and surface properties on particle resuspension rates. Aerosol Sci. Technol. 50: 339 352. https://doi.org/10.1080/02786826.2016.1152350

Lednicky, J.A., Shankar, S.N., Elbadry, M.A., Gibson, J.C., Alam, M.M., Stephenson, C.J., Eiguren-Fernandez, A., Morris, J.G., Mavian, C.N., Salemi, M., Clugston, J.R. and $\mathrm{Wu}, \mathrm{C} . \mathrm{Y}$. (2020). Collection of SARS-CoV-2 virus from the air of a clinic within a university student health care center and analyses of the viral genomic sequence. Aerosol Air Qual. Res. 20: 1167-1171. https://doi.org/10. 4209/aaqr.2020.05.0202

Li, A., Xiong, J., Yao, L., Gou, L. and Zhang, W. (2016). Determination of dust and microorganism accumulation in different designs of ahu system in shaanxi history museum. Build. Environ. 104: 232-242. https://doi.org/1 0.1016/j.buildenv.2016.05.014

Liu, Z., Zhu, Z., Zhu, Y., Xu, W. and Li, H. (2015). Investigation of dust loading and culturable microorganisms of hvac systems in 24 office buildings in Beijing. Energy Build. 103: 166-174. https://doi.org/10.1016/j.enbuild.20 15.06.056

López-Gómez, A., Castaño-Villar, A.M., Palop, A. and Marín-Iniesta, F. (2013). Hygienic design and microbial control of refrigeration and air conditioning systems for food processing and packaging plants. Food Eng. Rev. 5: 18-35. https://doi.org/10.1007/s12393-012-9060-1

Madelin, T.M. (1994). Fungal aerosols: A review. J. Aerosol Sci. 25: 1405-1412. https://doi.org/10.1016/0021-8502(9 4) $90216-\mathrm{x}$

Madsen, A.M. (2012). Effects of airflow and changing humidity on the aerosolization of respirable fungal fragments and conidia of botrytis cinerea. Appl. Environ. Microbiol. 78: 3999-4007. https://doi.org/10.1128/aem.0 7879-11

Mensah-Attipoe, J., Saari, S., Veijalainen, A.M., Pasanen, P., Keskinen, J., Leskinen, J.T.T. and Reponen, T. (2016). Release and characteristics of fungal fragments in various conditions. Sci. Total Environ. 547: 234-243. https://doi.org/10.1016/j.scitotenv.2015.12.095

Mims, C.W., Richardson, E.A. and Timberlake, W.E. (1988). Ultrastructural analysis of conidiophore development in the fungus aspergillus nidulans using freeze-substitution. Protoplasma 144: 132-141. https://doi.org/10.1007/bf01 637246

Nevalainen, A., Täubel, M. and Hyvärinen, A. (2015). Indoor fungi: Companions and contaminants. Indoor Air 25: 125-156. https://doi.org/10.1111/ina.12182
Nielsen, K.F. (2003). Mycotoxin production by indoor molds. Fungal Genet. Biol. 39: 103-117. https://doi.org/ 10.1016/s1087-1845(03)00026-4

Palmatier, R.N. (2007). Mold contamination and air handling units. J. Occup. Environ. Hyg. 4: 483-491. https://doi.org/10.1080/15459620701389909

Pasanen, A.L., Pasanen, P., Jantunen, M.J. and Kalliokoski, P. (1991). Significance of air humidity and air velocity for fungal spore release into the air. Atmos. Environ. 25: 459462. https://doi.org/10.1016/0960-1686(91)90316-y

Sannino, A., D’Emilio, M., Castellano, P., Amoruso, S. and Boselli, A. (2020). Analysis of air quality during the COVID-19 pandemic lockdown in Naples (Italy). Aerosol Air Qual. Res. https://doi.org/10.4209/aaqr.2020.07.0381

Sivasubramani, S.K., Niemeier, R.T., Reponen, T. and Grinshpun, S.A. (2004). Assessment of the aerosolization potential for fungal spores in moldy homes. Indoor Air 14: 405-412. https://doi.org/10.1111/j.1600-0668.2004.0 0262.x

Szulc, J., Okrasa, M., Dybka-Stępień, K., Sulyok, M., Nowak, A., Otlewska, A., Szponar, B. and Majchrzycka, K. (2020). Assessment of microbiological indoor air quality in cattle breeding farms. Aerosol Air Qual. Res. 20: 1353-1373. https://doi.org/10.4209/aaqr.2019.12.0641

Tucker, K., Stolze, J.L., Kennedy, A.H. and Money, N.P. (2007). Biomechanics of conidial dispersal in the toxic mold stachybotrys chartarum. Fungal Genet. Biol. 44: 641-647. https://doi.org/10.1016/j.fgb.2006.12.007

Wang, P., Yuan, S., Yang, N., Wang, A., Fordjour, A., and Chen, S. (2020). The collection method for crop fungal spores based on an efficient microfluidic device. Aerosol Air Qual. Res. 20: 72-79. https://doi.org/10.4209/aaqr.20 19.08.0424

Wang, S., Zhao, B., Zhou, B. and Tan, Z. (2012). An experimental study on short-time particle resuspension from inner surfaces of straight ventilation ducts. Build. Environ. 53: 119-127. https://doi.org/10.1016/j.buildenv. 2012.01.005

$\mathrm{Wu}, \mathrm{H}$. and Wong, J.W.C. (2020). The role of oxidative stress in the growth of the indoor mold cladosporium cladosporioides under water dynamics. Indoor Air 30: 117-125. https://doi.org/10.1111/ina.12613

Xiao, M., Wang, Q., Qin, X., Yu, G. and Deng, C. (2018). Composition, sources, and distribution of $\mathrm{PM}_{2.5}$ saccharides in a coastal urban site of China. Atmosphere 9: 274. https://doi.org/10.3390/atmos9070274

Zoberi, M.H. (1961). Take-off of mould spores in relation to wind speed and humidity. Ann. Bot. 25: 53-64. https://doi.org/10.1093/oxfordjournals.aob.a083732

Received for review, September 18, 2020 Revised, October 12, 2020 Accepted, October 16, 2020 